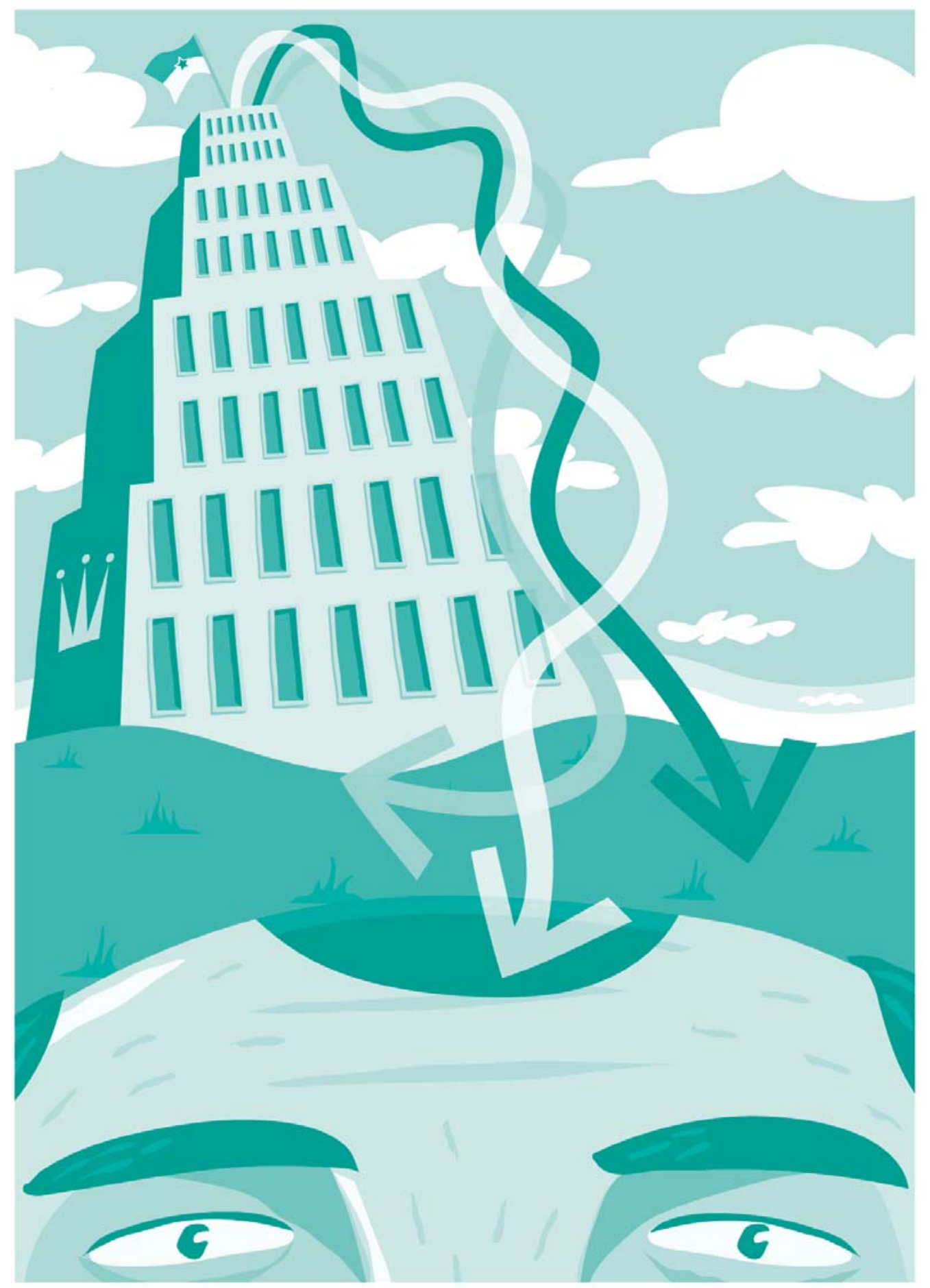




\section{Estudo sobre assessorias de comunicação social na esfera pública estadual: práticas profissionais e processo comunicacional}

Ana Maria Córdova Wels

- Doutora em Comunicação Social pelo Programa de Pós-Graduação em Comunicação da Faculdade de Comunicação Social da Pontifícia Universidade Católica do Rio Grande do Sul (Famecos-PUC-RS)

- Especialista em Administração pelo Programa de Pós-Graduação em Administração da Universidade Federal do Rio Grande do Sul (PPGA-UFRGS)

- Bacharel em Relações Públicas pela Famecos-PUC-RS

- anawels@terra.com.br 


\section{Resumo}

Na década de 1970, seguindo o modelo adotado, em nível federal, pela Assessoria Especial de Relações Públicas (Aerp), surgiram as primeiras assessorias de comunicação social junto a órgãos públicos no ramo executivo do Estado do Rio Grande do Sul. Para maior interlocução com a sociedade, tais assessorias tinham, entre suas principais atividades, a intermediação entre governos e mídia para o fornecimento de informações sobre atos governamentais e a conseqüente difusão da imagem pública.

PALAVRAS-CHAVE: ASSESSORIA DE COMUNICAÇÃO SOCIAL • ADMINISTRAÇÃO PÚBLICA • PRÁTICAS PROFISSIONAIS • PROCESSO COMUNICACIONAL

\section{Abstract}

The first consulting agencies in the field of social communication to public agencies in the executive sector of the state of Rio Grande do Sul emerged in the 70's, following a model already adopted in the federal level, with the constitution of the Special Agency of Public Relations. For the higher dialogue with the society, these consulting agencies had, as one of its main tasks, the mediation between the government and the media, to provide information about government actions and its subsequent public image spread.

KEYWORDS: COMMUNICATION CONSULTING AGENCIES • PUBLIC ADMINISTRATION • PROFESSIONAL ACTIONS - COMMUNICATION PROCESS

\section{Resumen}

La década de 70 fue el momento del surgimiento de las primeras asesorías de comunicación social junto a los órganos públicos del poder ejecutivo del estado del Rio Grande do Sul, según el modelo adoptado, en nivel federal, por la Asesoría Especial de Relaciones Públicas (Aerp). Para mayor interlocución con la sociedad, esas asesorías tenían, entre sus principales actividades, la intermediación de gobiernos y midia, para el suministro de informaciones sobre actos gubernamentales, y consecuente difusión de la imagen pública.

PALABRAS CLAVES: ASESORÍA DE COMUNICACIÓN SOCIAL • ADMINISTRACIÓN PÚBLICA • PRÁCTICAS PROFESIONALES - PROCESO COMUNICACIONAL 
$\mathrm{E}$ m sua origem, a história das Relações Públicas confunde-se com a história da formação das assessorias de comunicação, mediadoras de ações comunicativas entre organização e respectivos públicos. No Brasil, a trajetória não foi diferente e, ao longo do tempo, observamos, em distintos momentos, a sobreposição ou a intersecção das atividades de Jornalismo, de Relações Públicas e mesmo de Publicidade e Propaganda, atendendo a interesses das organizações para interlocução com seus públicos, num processo de consolidação do que atualmente chamamos de assessoria de comunicação social.

Ao estudar as assessorias de comunicação no âmbito governamental, ressaltamos o interesse, por parte da comunidade, em conhecer e acompanhar as ações do governo, assim como questões administrativas e aquelas relacionadas com a sociedade em geral. Neste sentido, há uma demanda externa permanente, a qual só pode ser atendida por meio de um projeto eficaz de comunicação que atenda e controle o fluxo de informações nesta esfera.

O presente estudo versa sobre as assessorias de comunicação social na esfera pública, com foco de observação nos órgãos do Executivo do Estado do Rio Grande do Sul, pontuando práticas profissionais desenvolvidas nesses núcleos. Para contextualizar o tema, apresentamos uma abordagem sobre a administração pública, o paradigma metodológico que amparou a pesquisa, os procedimentos metodológicos básicos adotados e, finalmente, a análise de resultados da investigação.

\section{Aspectos característicos da administração pública}

Inicialmente, é necessário dimensionar as principais características que definem uma administração pública, a fim de compor o cenário da pesquisa, ambientar o objeto de observação e compreender o papel das assessorias de comunicação como agente catalisador da comunicação entre administração pública e sociedade.

A administração refere-se à gerência e controle de pessoas e das atividades desenvolvidas por essas pessoas para atingir objetivos predeterminados, tratando-se de "um processo integrativo fundamental" (KWASNICKA, 1995, p. 17), que congrega e coordena esforços organizados que visam a propósitos comuns.

Waldo (1976, p. 6) define administração pública como "a organização e a gerência de 
homens e materiais para a consecução dos propósitos de um governo”. O autor a trata, ainda, como "a ciência e a arte da gerência aplicadas aos negócios do Estado" e Amato (1971, p. 17) agrega a idéia de exercício da ciência política, ao afirmar que "[...] administração pública significa política, sistema político, sistema de governo. Ou seja, o conjunto de manifestações da conduta humana que determina a distribuição e o exercício da autoridade pública, bem como o tratamento dos interesses públicos". A concepção de sistema encontra respaldo em White, que se refere ao "sistema de administração pública" como um "composto de todas as leis, regulamentos, práticas, relacionamentos, códigos e costumes que prevalecem sob qualquer tempo em qualquer jurisdição para o cumprimento ou execução da política pública” (WHITE, 1955 , p. 2). Essas abordagens levam ao entendimento sobre o processo de interatividade praticado por meio da prestação de serviços públicos voltados para as demandas da sociedade.

A administração pública incide, pois, sobre a prática do serviço público, que inclui "todas as profissões e todas as habilidades, dentro dos limites das funções e das atividades executadas para a comunidade" (LEISERSON; MARX, 1968, p. 59), alcançando todas as áreas governadas pela política pública.

Sobre a extensão da área pública, Marx (1968) e Amato (1971) entendem que o âmbito de ação da administração pública concentra-se, particularmente, no ramo executivo do governo, pois é nessa esfera do poder público que se encontram organizações e atividades que contêm pontos comuns com empresas privadas de produção econômica, e onde se estabelecem questões similares.

Trata-se, assim, da administração responsável pela determinação e execução de normas associadas a aspectos públicos e políticos, que se consolidam em ações das empresas estatais cuja natureza envolve o atendimento de interesses da sociedade em geral. Essas organizações são gerenciadas por políticos eleitos pelo povo ou nomeados por representantes legais, sendo mantidas por cofres públicos e, portanto, com compromisso direto com a comunidade. Ressalta-se, ainda, como característica da administração pública, a transitoriedade dos cargos administrativos ocupados por esses titulares, estabelecendo-se vínculo direto com o sistema político partidário, com o processo eleitoral e, conseqüentemente, com toda a sociedade.

Assim, entendido como um grande sistema, o gerenciamento dos negócios públicos envolve todas as atividades, serviços, ações e elementos constitutivos necessários para a execução do projeto de um Estado.

Considerada a amplitude na administração pública, conforme sua própria natureza determina, há que se estabelecer e manter um canal direto de comunicação entre o poder e a sociedade, suprindo a necessidade permanente de transmitir informações sobre decisões, ações, campanhas e discussões que se instalam no Governo. 

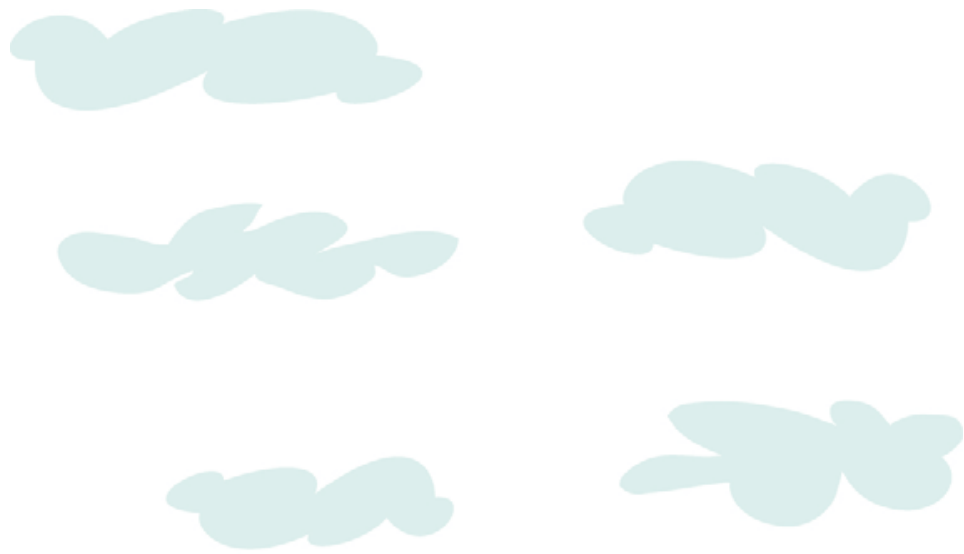

A necessidade dessa interlocução está definida no Plano Diretor da Reforma do Aparelho do Estado (BRASIL, 1995):

"A sociedade [...] manifesta seus anseios e demandas por canais formais e informais de contato com as autoridades constituídas. É pelo diálogo democrático entre o Estado e a sociedade que se definem as prioridades a que o Governo deve ater-se para a construção de um país mais próspero e justo". ${ }^{1}$

Nesse contexto, as assessorias de comunicação social da administração pública desenvolvem atividades de ponta, vinculando governo e sociedade por meio de ações que permitem o fluxo de comunicação nos dois sentidos.

\section{As organizações públicas}

As organizações públicas abrangem todas as "áreas e atividades governadas pela política pública" e, por meio delas, é possível "o exercício eficiente das funções civis confiadas ao ramo executivo do governo" (VIEG, 1968, p. 32).

Para Millett (1968, p. 149), a noção de organização pública remete, num primeiro momento, a uma "estrutura formal e ordenada, de grande envergadura, das repartições oficiais incumbidas de desempenhar as tarefas administrativas do governo". No entanto, o autor esclarece que com elas interagem "os órgãos criados para exercer as funções operacionais do governo, para administrar os programas públicos e desempenhar as missões efetivas julgadas necessárias ao bem-estar geral” (MILLETT, 1968, p. 149). Numa concepção ampla, organização pública e privada se assemelham. Entretanto, há fronteiras que percorrem os aspectos referentes à transitoriedade dos cargos pú-

1 Texto introdutório do Plano Diretor da Reforma do Aparelho do Estado (Brasil, 1995). 
blicos, políticas de pessoal, gerenciamento de finanças, projetos de desenvolvimento econômico e social, assim como de proteção dos interesses públicos.

Além desses aspectos, as organizações públicas caracterizam-se por um perfil burocrático em que a rigidez da estrutura hierárquica representa, muitas vezes, entraves para decisões e execução de serviços, repercutindo negativamente junto à opinião pública.

Quanto ao serviço público, seu objetivo é "proporcionar, amplificar e defender o bem comum", que consiste em atender "as necessidades básicas e secundárias de todos os homens de uma sociedade” (PERES, 1987, p. 97). O serviço público tem, pois, a função principal de prover o bem-estar do cidadão, beneficiando-o direta e indiretamente, e estabelecendo estreita relação entre bem-estar, bem comum e prestação de serviços.

Dada a abrangência do tema, a pesquisa sobre assessorias de comunicação social na área pública estadual está ancorada no Paradigma da Complexidade (MORIN, 2001).

\section{Princípios norteadores do pensamento complexo}

A idéia de complexidade é sintetizada por Morin quando o autor afirma que "o pensamento complexo é um pensamento que deve permitir ligar a autonomia e a dependência” (MORIN, 1996, p. 6). Encontra-se embutida nessa afirmação a noção de circularidade, que permite que se dimensione os fatos sempre dentro de um contexto, no qual se forma um anelamento com base em jogos de interações. Todo esse processo pressupõe formas de comunicação - e aqui se encontra a base do pensamento de Edgar Morin - em que ele inscreve todo o conhecimento humano e social.

O autor explica a complexidade:

"À primeira vista, a complexidade é um tecido (complexus: o que é tecido em conjunto) de constituintes heterogêneos inseparavelmente associados: coloca o paradoxo do uno e do múltiplo. Na segunda abordagem, a complexidade é efectivamente o tecido de acontecimentos, acções, interacções, retroacções, determinações, acasos, que constituem o nosso mundo fenomenal". (MORIN, 2001a, p. 20)

Etimologicamente, com-plexio é um vocábulo latino que tem, entre outros significados, o de "união, juntura, ligação"2. Hoje incorporado ao léxico português, traduz a

2 AZEVEDO, Fernando de (Org.). Pequeno dicionário latino-português. 8. ed. São Paulo: Companhia Editora Nacional, 1957. p. 14. 
idéia de conjunto em que os elementos formadores deste todo interagem entre si e com outros conjuntos por meio de inúmeras relações de interdependência, subordinação e dominação, que, de forma imbricada, permitem a observação de um mesmo objeto sob diferentes aspectos.

\section{Aspectos metodológicos da pesquisa: breve apresentação e procedimentos}

Para o desenvolvimento deste estudo, foi necessária a coleta de dados junto às assessorias de comunicação social dos órgãos da administração direta e indireta da esfera executiva do governo do Estado do Rio Grande do Sul. Foram aplicados dois tipos de questionários estruturados, gerando possibilidade de análise quantitativa e qualitativa. O levantamento foi realizado em dois momentos distintos — 2002 e 2003, chamando-se de Pesquisa 1 (P1) e Pesquisa 2 (P2) respectivamente.

A pesquisa comportou dois questionários que apresentaram dois direcionamentos distintos. O questionário I contemplou o núcleo de comunicação social como organização inserida em um órgão do Executivo, sendo encaminhado para ser respondido pelo responsável pelo núcleo observado. O questionário II destinou-se a cada um dos profissionais que atuavam nesses núcleos.

O questionário I teve por objetivo a compreensão das estruturas das assessorias, evidenciando recursos materiais e humanos disponibilizados na esfera pública, além das relações entre núcleo e organização, e entre eles próprios. Este questionário oportunizou, também, uma visualização dos períodos de criação dessas assessorias na linha do tempo. Além dessas variáveis, contemplou um elenco de atividades da área de comunicação social, discriminando e segmentando ações.

O questionário II destinou-se ao conhecimento do perfil acadêmico-profissional dos indivíduos que trabalham nas assessorias de comunicação social estudadas.

O retorno dos questionários da Pesquisa 1 (P1) encerrou-se em 30 de dezembro de 2002, haja vista que, a partir de janeiro de 2003 , houve mudança do governo estadual 3 . A aplicação dos questionários da Pesquisa 2 (P2) foi feita em dezembro de 2003. Para a tabulação dos dados, foi adotado procedimento de estatística descritiva, com elaboração de tabelas e gráficos correspondentes. No tratamento estatístico dos dados, para fins de definição das questões temporais, foram utilizadas como tempo referencial a data de 30 de dezembro de 2002 para a Pesquisa 1 (P1) e a data de 30 de dezembro de 2003 para a Pesquisa 2 (P2).

3 Em outubro e novembro de 2002 (dois turnos), houve eleições para o Governo do Estado, com posse em $1^{\circ}$ de janeiro de 2003. 


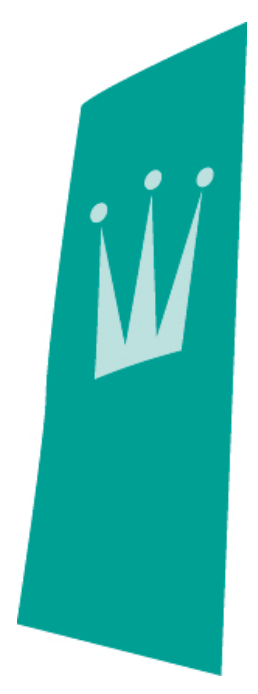

A partir da construção do marco teórico, a análise, realizada a partir da descrição e interpretação de informações obtidas, correspondeu a uma proposta de pesquisa quantitativa e qualitativa. Nesse tipo de pesquisa, há uma integração entre dados (surveys) e análise, permitindo-se uma leitura interpretativa de conteúdos respaldados por métodos quantitativos.

Ao afirmarem que "os dados não falam por si mesmos, mesmo que sejam processados com modelos estatísticos sofisticados”, Bauer, Gaskell e Allum (2003, p. 26) comungam com a idéia de que toda a pesquisa pode ser, ao mesmo tempo, quantitativa e qualitativa, pois os dados podem ser aproveitados para uma interpretação mais ampla acerca de um determinado fenômeno. Caso não haja essa leitura, os dados permanecem apenas como resultados estatísticos cuja objetividade se resume a números, percentuais, tabelas e gráficos.

A utilização de dados na análise de um fenômeno determinado projeta características de representatividade, fidedignidade e validade, tradicionalmente presentes na pesquisa quantitativa, para a pesquisa qualitativa (BAUER; GASKELL, 2003), atribuindo-lhe credibilidade quanto à seleção da amostra.

O levantamento de dados, utilizado como base no presente estudo, consiste em um elemento de suporte para o desenvolvimento da pesquisa. Com isso, conjuga-se a coleta e a análise descritiva dos dados, "permitindo uma idéia mais ampla e inteligível da complexidade de um problema" (GOLDENBERG, 2002, p. 62), ao mesmo tempo em que se constrói uma complementaridade entre os aspectos metodológicos quantitativo e qualitativo.

A informação estatística tem a propriedade de respaldar a pesquisa sobre as assessorias de comunicação social no Estado, à medida que oferece um mapeamento desses núcleos, suas vinculações, sua trajetória histórica, suas práticas e quadro profissional, somando-se à revisão bibliográfica, conceitual e documental que se agregam a este estudo. Existe, neste quadro, uma interdependência entre os "aspectos quantificáveis e a vivência da realidade objetiva no cotidiano” (GOLDENBERG, 2002, p. 62). 
Ainda neste sentido, Goldenberg (2002, p. 62) afirma que "a integração da pesquisa quantitativa e qualitativa permite que o pesquisador faça um cruzamento de suas conclusões de modo a ter maior confiança que seus dados não são produto de um procedimento específico ou de alguma situação particular”.

A essa combinação de diferentes metodologias para estudo de determinado fenômeno chama-se de técnica de triangulação $0^{4}$, que tem por objetivo "abranger a máxima amplitude na descrição, explicação e compreensão do foco em estudo" (TRIVIÑOS, 1987, p. 138). Isso pressupõe a necessidade de contextualizar, e não de isolar os fenômenos sociais, demandando que o pesquisador utilize diversos suportes teóricos e técnicos para seu trabalho.

$\mathrm{Na}$ abordagem metodológica deste trabalho, é importante reforçar que seu conteúdo está desenvolvido com base no Paradigma da Complexidade, conferindo uma abrangência interpretativa pertinente a pesquisas desta natureza.

\section{Relatório de pesquisa}

\section{Questionário I}

\section{Questões de Identidade e Identificação dos Núcleos de Comunicação}

A pergunta de abertura traz, para as Pesquisas 1 e 2 (P1 e P2), a informação de que $50 \%$ dos núcleos de comunicação observados pertencem à administração direta do Governo do Estado e 42,5\%, na P1, e 38\%, na P2, à administração indireta. Os dados sobre o tempo de criação dos núcleos de comunicação social também se aproximam, indicando percentuais de $40,9 \%$ (P1) e $52 \%$ (P2) de núcleos criados há mais de dez anos.

Observando-se a formação de núcleos de comunicação nessa linha de tempo, essa questão remete a algumas apreciações cabíveis. Segundo Torquato (2002, p. 3), "nas décadas de 1970 e 1980, a comunicação já assumia a escala de posicionamento estratégico nas organizações", justificando-se o surgimento de um expressivo número de núcleos de comunicação há mais de dez anos no setor público estadual. Por sua vez, é também no início dos anos 70 que aparece o primeiro registro de criação da Assessoria de Comunicação Social no Gabinete do Governador do Estado do Rio Grande do Sul, conforme o Decreto 21.079, de 25 de março de 1971.

4 Segundo Goldenberg (2002, p. 63), "triangulação é uma metáfora tomada emprestada da estratégia militar e da navegação, que se utilizam de múltiplos pontos de referência para localizar a posição exata de um objeto". 
A pergunta que solicita o nome formal dos núcleos de comunicação pesquisados tem um significado expressivo, pois é a identidade do núcleo. As ocorrências mais comuns se verificaram para o nome de Assessoria de Comunicação Social.

Legitimando o nível de importância de uma assessoria de comunicação no corpo organizacional, observa-se que, tanto na Pesquisa 1 quanto na Pesquisa 2, estes núcleos estão, em sua maioria $(89,7 \%$ na P1 e $91,7 \%$ na P2), vinculados ao maior nível hierárquico das instituições governamentais estudadas.

Este primeiro bloco de questões que tratam sobre a estrutura, nível hierárquico na instituição e nome de identidade conduz à discussão sobre o Princípio Sistêmico ou Organizacional (MORIN, 2000). As assessorias de comunicação social constituem um conjunto de organismos (assessoria-instituição, instituição-instituição, instituição-administração pública e administração pública-sociedade) que se inter-relacionam para compor um todo. Esses conjuntos e subconjuntos organizacionais comportam todas as características de sistema aberto apontadas por Littlejohn (1982): as partes se integram e reintegram, de acordo com seus propósitos; as partes interagem e se inter-relacionam; há uma ordem inicial nas relações entre as partes e os subconjuntos; há um processo de auto-regulação e controle promovido pelo ambiente externo que proporciona ajustes freqüentes; essa mesma relação com o meio ambiente permite o intercâmbio, estabelecendo uma relação dialógica; e, ainda, congregam, em princípio, objetivos comuns, os quais também se movimentam e se reorganizam.

A visão sistêmica das assessorias de comunicação, instituições, administração pública e sociedade confere às assessorias uma posição de meio e fim na organização. É meio à medida que subsidia a direção de uma organização com informações coletadas tanto no ambiente interno quanto no externo, possibilitando tomadas de decisão quanto a ações administrativas e ações comunicacionais. Torna-se atividade de ponta quando representa o portal da organização para divulgar e disseminar decisões, ações e campanhas que, lançadas no meio ambiente, promovem alterações que, igualmente, movimentam o sistema que circunscreve a própria organização.

Com essa perspectiva, cabe, ainda, fazer referência ao princípio hologramático, o qual contempla a representatividade da assessoria de comunicação, que assume papel de porta-voz de um sistema do qual também é parte. Esse papel é assumido tanto na esfera externa quanto na interna. Assim, a assessoria é portal e é elemento organizacional, traduzindo a organicidade presente em suas ações.

Questões referentes às rotinas e atividades das áreas de Relações Públicas, Jornalismo e Publicidade e Propaganda

Os itens do questionário I, que se referem às atividades desenvolvidas nos núcleos de comunicação inerentes às áreas de Relações Públicas, Jornalismo e Publicidade, res- 
pectivamente, apontam para o que segue (foi considerada a freqüência de ocorrência mínima de um percentual de $60 \%$ de núcleos que praticam as rotinas indicadas):

- Quanto às atividades internas, na Pesquisa 1 (P1), ganham destaque a criação e implantação de programas de apresentação das instituições (62,5\%); organização e acompanhamento de reuniões internas (60\%); organização e execução de festividades e homenagens (92,5\%); elaboração e manutenção de cadastro de datas alusivas (60\%); elaboração de programas de comunicação interna (65\%); confecção e distribuição de boletim informativo interno (65\%); manutenção de quadro mural (85\%); divulgação interna sobre participação da instituição na mídia (65\%); organização e manutenção de arquivo de fotos da instituição (77,5\%). Na Pesquisa 2, destacam-se criação e implantação de programas de apresentação das instituições (60\%); organização e acompanhamento de reuniões internas (60\%); organização e execução de festividades e homenagens (74\%); elaboração de programas de comunicação interna (62\%); divulgação interna sobre participação da instituição na mídia (72\%); organização e manutenção de arquivo de fotos da instituição (74\%).

- Em relação às atividades de Relações Públicas desenvolvidas junto ao público externo da instituição, a Pesquisa 1 assinalou maior freqüência em relação ao planejamento e execução de malas diretas institucionais (80\%); elaboração e manutenção de mailing (85\%); planejamento e implantação de campanha institucional (75\%); elaboração de audiovisual sobre a instituição (60\%); participação na confecção da homepage da instituição (75\%); planejamento, agendamento e acompanhamento de visitas externas à instituição (65\%). A Pesquisa 2 apontou destaque apenas para os itens elaboração e manutenção de mailing (70\%) e participação na confecção da homepage da instituição (74\%).

- O item referente à promoção e organização de eventos, inserido dentre as atividades de Relações Públicas, foi expressivo tanto na Pesquisa 1 quanto na Pesquisa 2, indicando percentuais em torno de $90,5 \%$ nos núcleos estudados na P1, e de $73 \%$ nos núcleos observados na P2.

- Na seqüência, observam-se as atividades de imprensa, cujo primeiro item pergunta sobre ações de relacionamento entre as assessorias de comunicação social e a mídia, que contemplam elaboração e encaminhamento de releases, atendimento a demandas de mídia, convocação e acompanhamento de coletivas e leitura e taxação de matérias jornalísticas. É interessante observar que as Pesquisas 1 e 2 trazem o registro de percentuais entre 90 a 100\% para o número de núcleos de comunicação que desenvolvem as ações de imprensa acima apontadas. Esse expressivo indicador referenda a discussão recorrente de que algumas assessorias de comunicação social intitulam-se assessorias de imprensa por priorizarem ações na área de relacionamento com a mídia.

- Nas demais ações de imprensa, há uma equivalência entre alguns percentuais levantados nas Pesquisas 1 e 2: participação na confecção da homepage da instituição ( $90 \%$ e $84 \%)$ e realização de trabalho fotográfico de eventos promovidos pela instituição ( $87,5 \%$ e $86 \%)$. 
- A questão da participação na elaboração da homepage aparece, nas duas pesquisas, como atividade conjunta, pertencendo, simultaneamente, às áreas de Relações Públicas e Imprensa.

- As atividades relativas a questões de Publicidade e Propaganda, no Governo do Estado, concentram-se em órgãos que trabalham diretamente com campanhas públicas institucionais, entre as quais as áreas da saúde, transporte, segurança, meio ambiente e educação, para citar alguns. O processo de escolha de agências para o desenvolvimento dessas campanhas é centralizado, em vista dos trâmites licitatórios 5 exigidos no âmbito da administração pública. Esses procedimentos centralizados restringem o trabalho de execução de peças nos núcleos de comunicação dos diferentes órgãos, cabendo-lhes ações relativas a planejamento, administração, supervisão, acompanhamento e avaliação, além do trabalho conjunto com as agências.

\section{Relações e fluxos de informação entre os núcleos de comunicação}

Ao perguntar se o núcleo de comunicação se relaciona freqüentemente com os funcionários da instituição, há uma aproximação no número de respostas das Pesquisas 1 e 2: na P1, 80\% dos núcleos responderam 'Sim' e 17,5\%, 'Em parte'. Na P2, 78\% dos núcleos responderam 'Sim' e 14\%, 'Em parte'.

A pergunta para aferir se os funcionários da instituição conhecem o trabalho desenvolvido pelo núcleo de comunicação também mantém uma aproximação, permitindo que seja inferido que, ao longo de um ano, que é o período que distancia uma pesquisa da outra, houve certa constância. $\mathrm{Na}$ P1, registrou-se a freqüência de $47,5 \%$ para a resposta 'Sim' e 52,5\% para 'Em Parte'. Na P2, registrou-se 44\% para 'Sim', e 56\% para a resposta 'Em parte'.

Quando se procura saber se os funcionários da instituição procuram o núcleo de comunicação para obter orientação sobre formas de divulgação de trabalhos, repete-se a mesma tendência à estabilidade quanto ao percentual de respostas afirmativas para a Pesquisa 1 e para a Pesquisa 2. Na P1, registrou-se 60\% de resposta 'Sim' e 37,5\% 'Em parte'. Na P2, observa-se o mesmo percentual de 60\% para 'Sim' e 30\% ‘Em parte'.

No questionário, abre-se uma relação de itens que confirmam a colaboração de outros setores para com os núcleos de comunicação social. Essas formas de colaboração concentram-se, em primeiro lugar, em alimentar os núcleos de comunicação com informações sobre projetos e atividades institucionais que precisam de divulgação, tanto interna quanto externa e na mídia. Assim, 67,5\% dos respondentes da P1 afirma-

5 Licitação consiste na escolha, por meio de concorrência pública, de fornecedores de produtos ou serviços para órgãos públicos, conforme edital previamente publicado em jornais. 
ram que recebem essa colaboração, equilibrando-se com os 64\% da P2. Quanto ao encaminhamento de material para divulgação (cartazes e avisos de interesse interno), $67,5 \%$ dos núcleos pesquisados na P1 confirmaram que 'Sim' e apenas 38\% dos núcleos observados na P2 responderam afirmativamente. Sobre o envolvimento de outros setores nas promoções de eventos e o comparecimento de colegas para prestigiarem esses encontros, 52,5\% dos núcleos da P1 responderam 'Sim', registrando-se, na P2, um percentual $66 \%$ de respostas afirmativas, o que evidencia integração entre núcleos de uma mesma instituição.

No item que pergunta se os demais setores se manifestam quanto às ações praticadas internamente pelos núcleos de comunicação das instituições, a P1 registrou que $85 \%$ dos núcleos recebem manifestação total ou parcial de colegas, enquanto a P2 indicou que $80 \%$ conta com essa participação, revelando esses expressivos percentuais que há interlocução entre os setores e reconhecimento institucional quanto aos núcleos de comunicação.

Ainda no item sobre relacionamentos, especificamente quanto a formas de comunicação que se estabelecem com os núcleos de outras instituições, observa-se que a maioria dos contatos se efetiva por telefone e por e-mail (na P1, 95\% e 90\% respectivamente e na $\mathrm{P} 2,88 \%$ e $86 \%$ ). Outros encontros são propiciados por reuniões agendadas pela Secretaria de Comunicação (na P1, 75\%; na P2, 50\%) e quando há necessidade de realização de atividades conjuntas entre núcleos.

\section{Equipamentos e recursos materiais disponibilizados aos núcleos de Comunicação Social das instituições estaduais}

Quanto aos recursos materiais dos núcleos de comunicação no Estado, optou-se apenas por apresentar os resultados levantados nas P1 e P2, não cabendo observações teóricas acerca desses dados. Assim, as pesquisas apontaram que a maioria dos núcleos de comunicação dispõe de equipamentos, tais como linhas telefônicas internas e externas, microcomputadores, impressoras, scanner, aparelhos de fax, fotocopiadoras, aparelhos de rádio, TV e vídeo cassete, e máquinas fotográficas. Ficam mais restritas as máquinas filmadoras e aparelhos de datashow.

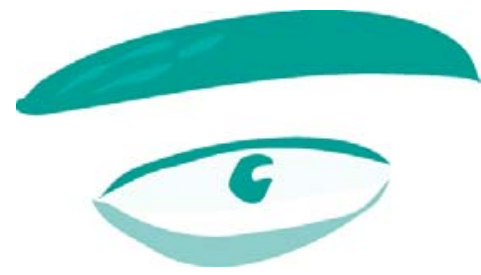


A disponibilidade desses equipamentos nos núcleos de comunicação indica um grau de maturidade quanto ao reconhecimento das necessidades de recursos materiais para essa área de trabalho no Estado, pois sabe-se que, em razão dos trâmites exigidos para aquisição de bens no setor público, é necessário que se justifique satisfatoriamente cada compra que é realizada.

Sugestões dos núcleos de comunicação para otimização das ações de Comunicação Social no Estado: uma questão aberta

É interessante registrar que apenas 17,5\% dos núcleos estudados na Pesquisa 1 responderam à questão, correspondendo a um número de sete questionários. Na Pesquisa 2 , este número dobra para 15 , equivalendo a $31 \%$ dos núcleos pesquisados.

Na Pesquisa 1, são apresentadas sugestões diversificadas: a confecção de um boletim eletrônico das assessorias de comunicação do Estado; a reivindicação de equipamentos e de novas assinaturas de jornais; a descentralização de decisões e iniciativas; a promoção de maior integração entre assessores e mídia; a necessidade de que cada núcleo conte com profissionais das três áreas da comunicação; maior intercâmbio entre assessorias de comunicação; e realização de reuniões entre assessorias.

A Pesquisa 2 concentra suas sugestões em itens que reivindicam a realização de um projeto integrado de comunicação social; o estabelecimento de políticas e prioridades da administração; maior articulação e integração entre os setores da comunicação do Estado; também, a realização de reuniões e encontros regulares para intercâmbio entre as assessorias.

Na seqüência, a apresentação dos dados relativos ao questionário II.

\section{Questionário II}

Perfil dos profissionais que atuam nos núcleos de comunicação social da administração executiva do Governo do Estado do Rio Grande do Sul

O questionário II destinou-se a todos os funcionários que atuam nas assessorias de comunicação social estudadas. Para atender a essa proposta, o questionário foi respondido, também, pelos funcionários que atuam, diretamente, junto ao Gabinete do Governador, incluindo, nesse conjunto, assessores da Secretaria de Comunicação, Cerimonial e Protocolo, Central de Eventos e Casa Civil. O questionário II abrange, portanto, uma população de tamanho desconhecido, contabilizando-se, para a Pesquisa 1, o tamanho amostral de 247 respondentes e, para a Pesquisa 2, o tamanho de 203 respondentes. Neste caso, não é possível predeterminar a amostra, pois o controle da distribuição dos questionários nas assessorias ficou a cargo dos responsáveis de cada setor. 
A questão de abertura do questionário II diz respeito à situação funcional, e apresentou um cenário em que, na Pesquisa 1, havia $25,9 \%$ dos funcionários pertencentes ao quadro das próprias instituições onde atuavam, enquanto 32,8\% eram Cargos em Comissão ${ }^{6}$ (CCs) e 32,8\% de estagiários. Na Pesquisa 2, os funcionários do quadro ocupam $32 \%$ do total e os Cargos em Comissão representam, igualmente, outros $32 \%$ do total pesquisado. Na P2, os estagiários formam um contingente de $25,6 \%$.

Tanto na P1 quanto na P2, os estagiários são, em sua maioria, estudantes do curso de Jornalismo (55,7\% na P1 e 61,5\% na P2), seguidos pela área de Relações Públicas na P1 (20,3\%) e pela área de Publicidade e Propaganda na P2 (23,1\%). Também representam maioria, nas duas pesquisas, os funcionários-colaboradores com curso superior $(56,5 \%$ e $63,6 \%$, respectivamente).

Nas áreas de formação, sobressai-se de maneira expressiva, nas duas pesquisas, a formação jornalística (63,44\% na P1 e 63,22\% na P2), seguida pelas Relações Públicas e pela Publicidade e Propaganda.

A maioria dos funcionários que atua nas assessorias possui apenas um curso superior e, dentre estes, destaca-se a formação em Jornalismo. Quanto à qualificação e formação em cursos de pós-graduação, o quadro de assessores de comunicação do Estado contava com $17,2 \%$ de seus funcionários com nível de especialização em dezembro de 2002 (P1), e com 20,2\% de funcionários com especialização em dezembro de 2003 (P2).

Ainda com referência aos funcionários com cursos de pós-graduação ${ }^{7}$, a P1 apresenta um percentual de 6,2\% com nível de mestrado e 1,3\% com nível de doutorado. Esses indicadores apresentam pequena variação na P2, assinalando 10,5\% para o nível de mestrado e $2,4 \%$ para o nível de doutorado.

A procedência dos profissionais atuantes nos núcleos de comunicação do Estado é variável, revelando que a maioria tem origem em assessorias de comunicação (pública e privada), seguidos por colegas oriundos de empresas jornalísticas.

A maioria dos respondentes dos questionários nas Pesquisas 1 e 2 comungam com a idéia de que a formação acadêmica oferece a base teórica fundamental para o exercício das atividades desenvolvidas nos núcleos de comunicação. É também representa-

6 Os Cargos em Comissão (CC) são cargos ocupados por tempo determinado e as respectivas nomeações são assinadas pelo Governador do Estado e publicadas no Diário Oficial do Estado do Rio Grande do Sul.

7 No momento da tabulação do item 5 do Questionário II, nas Pesquisas 1 e 2, considerou-se as categorias de Mestrado e Doutorado para funcionários com titulação e/ou em curso. 
tivo o número de opiniões que agregam a vivência da prática profissional à importância do conhecimento acadêmico, considerando que a experiência contribui para complementar o aprendizado teórico.

Feitas as considerações estatísticas sobre o corpo funcional das assessorias de comunicação social, emerge, para fins de análise, o princípio da reintrodução, em que se coloca o indivíduo-sujeito no centro de todas as ações e interações, consistindo, ele próprio, em um sistema complexo e organizado que comporta todos os princípios do paradigma da complexidade.

Assim, ao enfocar o indivíduo-sujeito como agente comunicacional atuante nos núcleos de comunicação, é possível propor uma nova dimensão às atividades desenvolvidas nessa área, compreendendo não só sua estrutura organizacional/funcional, mas, para além disso, o papel social e cultural que uma assessoria de comunicação pode desempenhar.

\section{Considerações finais}

O levantamento quantitativo realizado junto aos núcleos de comunicação estudados permitiu a construção de um quadro estatístico de base para a análise do objeto selecionado. As respostas dos questionários produziram um mapeamento da identidade, práticas, rotinas e recursos materiais das assessorias e delinearam o perfil profissional e acadêmico de seus integrantes.

Entretanto, embora os questionários tenham sido aplicados em dois momentos diferentes, com intervalo de tempo de um ano, conforme descrição do tempo referencial definido para as Pesquisas 1 e 2, verificaram-se diversos pontos de convergência nas respostas, não tendo sido observadas, nas amostras dos questionários aplicados, divergências significativas.

Isso remete a outra consideração relevante. A Pesquisa 1 foi realizada no último ano de um governo estadual e a Pesquisa 2 foi realizada no primeiro ano de uma nova gestão governamental. Embora os questionários não contemplassem aspectos de ordem político-partidária, atendo-se a questões referentes à estrutura, às práticas e ao pessoal lotado nas assessorias de comunicação, sabe-se que o processo de sucessão governamental acarreta mudanças estruturais e funcionais, principalmente em cargos de coordenação. Mesmo com esse panorama previamente conhecido, observou-se continuidade nas práticas das assessorias de comunicação, conferindo-lhes o caráter autônomo, embora dependente, que se explica por meio do princípio da auto-eco-organização e no princípio dialógico, tão inerente ao processo comunicativo.

Partindo-se, então, dessa observação de auto-organização das assessorias de comuni- 
cação no Estado, é possível, ainda, perceber que as assessorias de comunicação estão legitimadas na seara pública.

Observou-se que os núcleos de comunicação pesquisados desenvolvem ações nas áreas de Relações Públicas e de Jornalismo e, em alguns órgãos, de Publicidade, destacando-se aquelas que se vinculam à imprensa. Em relação a esse dado, é necessário refletir acerca de alguns fatos que sinalizam a origem das ações de comunicação ligadas ao assessoramento nas empresas. É fato que, no início do século passado, nos Estados Unidos, o jornalista Ivy Lee se destacou atuando na função de Relações Públicas, intermediando o relacionamento entre a organização e a mídia para difundir, por meio dos veículos de comunicação, informações que se destinavam à formação de uma opinião pública favorável.

No Governo estadual onde se ambienta esta pesquisa, observou-se a participação de um maior número de profissionais e estagiários do curso de Jornalismo lotados nas assessorias, seguidos por colegas das outras duas áreas (Relações Públicas e Publicidade). Esse dado reforça a concepção de que as assessorias concentram ações nas relações com a mídia, seguindo-se as de promoção de eventos, considerados expressivo instrumento de comunicação.

Contudo, as respostas assinaladas nos questionários indicam que grande parte dos núcleos investigados trabalha e atua nas três áreas da comunicação. Esse indicador é favorável para toda a análise do estudo, pois possibilita entender a assessoria de comunicação social como uma organização integrada, assumindo função de pórtico comunicacional.

Nesse particular, cabe ressaltar que a comunicação desenvolvida na esfera pública pode ser entendida como um processo permanente de busca de interlocução e interação entre governos e sociedade. Ela se estabelece por meio da representatividade dos órgãos públicos e pode ser potencializada pelas assessorias de comunicação, por meio de programas específicos.

À medida que se indica a legitimidade de assessorias em órgãos públicos, percebe-se a relevância em institucionalizar a área de comunicação dentro dessas organizações, desenvolvendo projetos, profissionalizando serviços e ampliando redes que promovam integração, as quais se iniciam no âmbito interno e se estendem para além das fronteiras organizacionais. No setor público, essa concepção permeia todos os cidadãos que integram a sociedade, atuando dentro e fora dessas instituições.

A pesquisa em pauta pretende oferecer uma contribuição que contempla um momento que é presente e um tempo que é futuro. No presente, oferece-se um mapa, configurando uma situação que traz um histórico e mostra uma realidade. Em um tempo futuro, espera-se que os caminhos aqui abertos tenham continuidade, e que novas 
ESTUDO SOBRE ASSESSORIAS DE COMUNICAÇÃO SOCIAL NA ESFERA PÚBLICA ESTADUAL: PRÁTICAS PROFISSIONAIS E PROCESSO COMUNICACIONAL • ANA MARIA CÓRDOVA WELS

pesquisas sejam agregadas. Assim, será possível o exercício de todos os princípios do pensamento complexo para a renovação e atualização constante e recorrente dos conceitos e propostas contidas em uma investigação.

\section{Bibliografia}

AMATO, Pedro Muñoz. Introdução à administração pública. 2. ed. Rio de Janeiro: Fundação Getúlio Vargas, 1971.

ANDRADE, Cândido Teobaldo de. Para entender relações públicas. 4. ed. São Paulo: Loyola, 1993.

Curso de relações públicas. 6. ed. São Paulo: Pioneira Thomson Learning, 2003.

BAUER, Martin; GASKELL, George; ALLUM, Nicholas. Qualidade, quantidade e interesses do conhecimento. In: BAUER, Martin; GASKELL, George. Pesquisa qualitativa com texto, imagem e som. 2. ed. Petrópolis: Vozes, 2003. p. 17-36.

BAUER, Martin; GASKELL, George. Para uma prestação de contas pública: além da amostra, da fidedignidade e da validade. In: BAUER, Martin; GASKELL, George. Pesquisa qualitativa com texto, imagem e som. 2. ed. Petrópolis: Vozes, 2003. p. 470-490.

BRASIL. Ministério da Administração Federal e Reforma do Estado (MARE). Plano diretor da reforma do apareIho do Estado. Brasília, Presidência da República, Imprensa Oficial, 1995. Disponível em: <https://www.presidencia.gov.br/publi_04/COLECAO/PLANDI2.HTM>. Acesso em: 29 set. 2003.

GOLDENBERG, Mirian. A arte de pesquisar: como fazer pesquisa qualitativa em ciências sociais. 6 . ed. Rio de Janeiro: Record, 2002.

KWASNICKA, Eunice Lacava. Introdução à administração. 5. ed. rev. e ampl. São Paulo: Atlas, 1995.

LEISERSON, Avery; MARX, Fritz Morstein. A formulação de diretrizes administrativas. In: MARX, Frits Morstein (Org.). Elementos de administração pública. São Paulo: Atlas, 1968. p. 353-367.

LITTLEJOHN, Stephen. Fundamentos teóricos da comunicação humana. Rio de Janeiro: Zahar, 1982.

MARX, Fritz Morstein (org.) Elementos de administração pública. São Paulo: Atlas, 1968.

- A função social da administração política. In: MARX, Fritz Morstein. Elementos de administração pública. São Paulo: Atlas, 1968. p. 113-132.

MILLETT, John. Conceitos de organização, In: MARX, Fritz Morstein. Elementos da administração pública. São Paulo: Atlas, 1968. p. 149-164.

MORIN, Edgar. Da necessidade de um pensamento complexo. In: MARTINS, Francisco Menezes; SILVA, Juremir Machado da. Para navegar no século XXI. 2. ed. Porto Alegre: Sulina/EDIPUCRS, 2000. p. 19-42.

. Introdução ao pensamento complexo. 3. ed. Lisboa: Instituto Piaget, 2001a.

. O método l: a natureza da natureza. 2. ed. Portugal: Publicações Europa-América, 1977. 
ESTUDO SOBRE ASSESSORIAS DE COMUNICAÇÃO SOCIAL NA ESFERA PÚBLICA ESTADUAL: PRÁTICAS PROFISSIONAIS E PROCESSO COMUNICACIONAL • ANA MARIA CÓRDOVA WELS

O método Il: a vida da vida. Porto Alegre: Sulina, 2001b.

O método III: o conhecimento do conhecimento. Porto Alegre: Sulina, 1999.

. O método IV: as idéias - habitat, vida, costumes, organização. 2. ed. Porto Alegre: Sulina, 2001c.

. A cabeça bem-feita: repensar a reforma, reformar o pensamento. 8. ed. Rio de Janeiro: Bertrand Brasil, 2003.

. Política de civilização e problema mundial. Revista da FAMECOS, Porto Alegre, n. 5, p. 7-13, dez. 1996.

PERES, José Augusto de Souza. Serviço público e bem comum. In: CASTOR, Belmiro Valverde et al. Estado e administração pública. Brasília: FUNCEP, 1987. p. 87-117.

RIO GRANDE DO SUL. Coletânea de leis e decretos estaduais. Porto Alegre: Secretaria da Administração, 19692003.

. Constituição do Estado do Rio Grande do Sul. 8. ed. Porto Alegre: CORAG, 2000.

SEABRA, Sérgio Nogueira. A nova administração pública e mudanças organizacionais. Revista de Administração Pública, Rio de Janeiro, v. 35, n. 4, p. 19-43, jul./ago. 2001.

SERRA E GURGEL, J. B. Assessoria de imprensa: um roteiro para especialização. Jornal ANJ, Brasília, dez. 98/jan. 99.

TORQUATO, Francisco Gaudêncio. Comunicação empresarial / comunicação institucional: conceitos, estratégias, sistemas, estrutura, planejamento e técnicas. São Paulo: Summus, 1986.

Tratado de comunicação organizacional e política. São Paulo: Pioneira Thomson Learning, 2002.

TRIVIÑOS, Augusto N. S. Introdução à pesquisa em ciências sociais: a pesquisa qualitativa em educação. São Paulo: Atlas, 1987.

VIEG, John A. O desenvolvimento da administração pública. In: MARX, Fritz Morstein. Elementos da administração pública. São Paulo: Atlas, 1968. p. 29-48.

WALDO, Dwight. O estudo da administração pública. 2. ed. Rio de Janeiro: FGV, 1976.

WHITE, Leonard D. Introduction to the study of public administration. 4. ed. New York: The Macmillan Company, 1955.

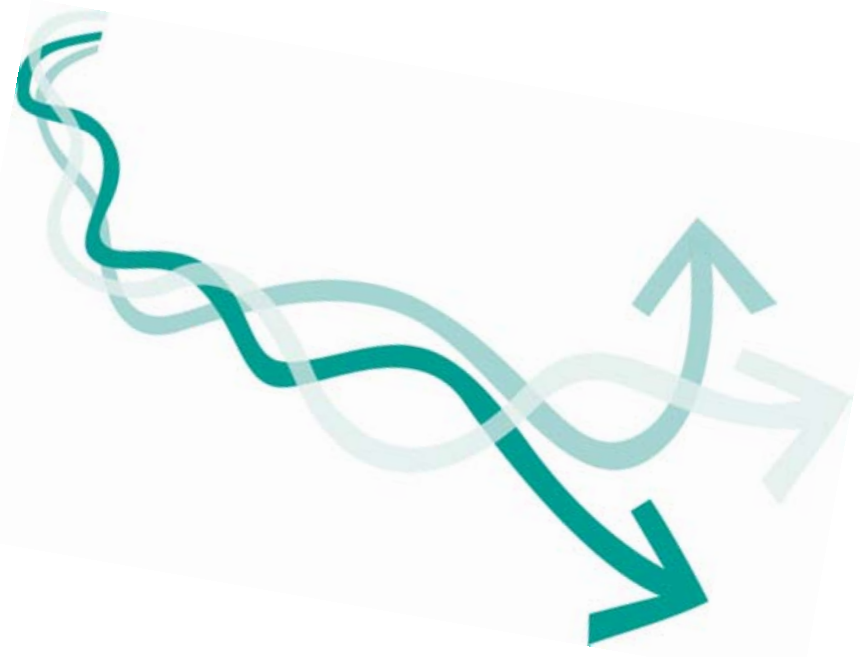

